\title{
IS6110 restriction fragment length polymorphism typing of Mycobacterium tuberculosis isolates from East Azerbaijan Province of Iran
}

\section{Mohamad Asgharzadeh, Karen Shahbabian*/+ , Jafar Majidi, Ahmad Mirza Aghazadeh, Cirus Amini**, Ali Reza Jahantabi*, Abdolnaser Rafi**}

Drug Applied Research Center *Department of Microbiology, School of Medicine **Research Center for TB and Pulmonary Diseases, Tabriz University of Medical Sciences, Tabriz, Iran

To investigate the genetic variation among Mycobacterium tuberculosis isolates in the East Azerbaijan Province of Iran and to evaluate the level of and risk factors for recent transmission of tuberculosis (TB), we performed IS6110-based restriction fragment length polymorphism analysis of strains, isolated from 105 patients during the period of September 2002 to March 2003 in TB centers and university hospitals of the province. Among 105 isolates, 81 different IS6110 patterns were found, of which 70 were observed only once and 11 were shared by two to eight isolates. Ninety-six isolates (91.4\%) were found to have more than five copies of IS6110 and together with high patterns polymorphism, shows that IS6110-RFLP typing could be useful for studying the epidemiology of TB in Azerbaijan. The minimum estimated rate of recent transmission was 23\%, suggesting that the degree of recent transmission in East Azerbaijan Province is relatively low. Clustering was not associated with age, sex or site of infection of TB but drug-resistant isolates were less likely to be clustered than sensitive isolates $(p<0.05)$.

Key words: tuberculosis - restriction fragment length polymorphism - IS6110 - Iran

DNA fingerprinting of Mycobacterium tuberculosis is a valuable tool to study tuberculosis (TB) epidemiology. Many other studies on this methodology have been done in various parts of the world including developed and developing countries (Pineda-Garcia et al. 1997, Gutierrez et al. 1998, Dahle et al. 2001, Diaz et al. 2001, Bhanu et al 2002). The method of fingerprinting based on IS6110 repetitive element has become standard (Hermans et al. 1990, Van Embden et al. 1993) and its stability (Niemann et al. 2000, Warren et al. 2002) and discriminatory power have been proven (Kremer et al. 1999).

The usefulness of DNA fingerprinting has already been defined in source tracing (Kiers et al. 1997) and understanding of TB transmission in the general population (Alland et al. 1994). Fingerprinting results from various parts of the world demonstrate that in areas with low incidence of TB, the majority of cases are due to reactivation of previous infection whereas in high incidence areas reinfection is responsible for the majority of TB cases (Alland et al. 1994, Dahle et al. 2001) but there are some exceptions (Bauer et al. 1998, Narayanan et al. 2002).

The East Azerbaijan Province is located in the North West of Iran, in neighbor-hood of Nakhichevan state of Republic of Azerbaijan (Fig. 1A). The estimated population of the Province is 3,500,000 of which about two-fifth are inhabitants of Tabriz, the capital city of the Province.

Financial support: Drug Applied Research Center, Tabriz University of Medical Sciences

+Corresponding author: karenbsb@yahoo.com

Received 6 December 2005

Accepted 30 May 2006
The estimated rate of TB in Iran in 2002 was 29 in 100,000 and notification rate is 17 in 100,000 (WHO 2004). However, TB incidence is not homogeneous in different parts of this country. In East Azerbaijan Province the estimated rate of TB in 2002 was low; this can be due both to low case finding or low prevalence of TB in this part of the country.

The aims of this study were to determine the genetic diversity of $M$. tuberculosis population in East Azerbaijan Province, and to detect the manner of transmission of the disease in this area.

\section{MATERIALS AND METHODS}

Patient population and bacterial isolates - The study population comprised all patients with TB confirmed by culture from September 2002 to March 2003 in TB centers and university hospitals of the province. Information about age, sex, geographical origin, and history of tuberculosis were recorded.

The species identification of the isolates was based on polymerase chain reaction (PCR) method and standard microbiological tests. The susceptibilities of the isolates to isoniazid (INH), rifampin (RF), streptomycin (SM), and ethambutol (ETB) were determined by the proportional method.

Restriction fragment length polymorphism analysis RFLP analysis was performed as described previously (Van Soolingen et al. 1994). Briefly, extracted mycobacterial DNA was digested with PvuII, subjected to electrophoresis, and hybridized with a 245-bp PCR-amplified probe directed against the right arm of IS6110. After hybridization, the insertion sequences were visualized with a colorimetric system, the DIG DNA labeling and detection kit (Roche, Germany) by following the manufacturer's instructions. A mixture of PvuII-digested supercoiled DNA ladder (Sigma) 
and HaeIII-digested $\Phi X 174$ DNA (Fermentas) was used as an internal marker. PvuII-digested genomic DNA of $M$. tuberculosis reference strain Mt14323 was used as an external marker in each gel (Van Embden et al. 1993). The IS6110 fingerprint patterns were compared by visual examination. A cluster of M. tuberculosis was defined as two or more isolates which exhibited the same number of copies of the IS6110 fragment with identical molecular sizes. The IS6110 RFLP patterns obtained from this region were compared to those, available from previous studies in various parts of the country.

Statistical analysis was carried out by using the chisquare test (or Fisher's exact test, when expected values were five or less) and student's t-test. P values below 0.05 were considered statistically significant.

\section{RESULTS}

Patients and isolates - During the study period, out of 154 samples that were collected and submitted for culture, $125(81 \%)$ M. tuberculosis isolates have been obtained. Clinical isolates were recovered from sputum $(\mathrm{n}=$ 97), bronchial fluids $(n=19)$, abscess aspirates $(n=2)$, urine $(n=2)$, cerebrospinal fluids $(n=2)$, pleural fluid $(\mathrm{n}=1)$, endometrial biopsy $(\mathrm{n}=1)$, and neck mass biopsy $(n=1)$. Six of the isolates could not be used for RFLP analysis; therefore the RFLP patterns of 119 isolates from 119 patients were determined. Fourteen strains were excluded because they were isolated from Nakhichevaneese patients, but the patterns compared with Iranian strains' patterns for detecting probable transmission of the infection. Therefore, our study group consisted of 105 patients, who had no history of previous TB. The age of the patients ranged from 12 to 90 years which young patients ( $\leq 45$ yrs old) represented $43 \%$ of study population. The male to female ratio was 1.3:1. Eighty-one (77\%) of the 105 strains were susceptible to INH, RF, SM, and ETB. Twentythree percent of the strains were found to be resistant to at least one drug, with $15.2 \%$ of the strains resistant to $\mathrm{SM}, 9.5 \%$ resistant to INH, $5.7 \%$ resistant to RF, and one strain resistant to ETB. Among these strains, two strains were multi-drug-resistant (MDR).

IS6110 RFLP clustering - The copy number of IS6110 in each of the isolates was determined from the number of bands hybridizing with the probe. The number of IS6110 copies per isolates varied from zero to 18 . Most strains $(91.4 \%)$ carried six or more IS6110 copies. Nine strains (8.6\%) contained less than six copies of IS6110, of which four strains had five copies, one strain had four copies, one strain had three copies, and three strains had no copies of IS6110; none of the low-copy number patterns (except zero-copy patterns) belonged to a cluster. Eightyone distinct IS6110 RFLP patterns were revealed: 70 of these patterns were unique and 11 were shared by two to eight strains. Thirty-five strains (33.3\%), belonging to one of 11 clusters (Fig. 1B) were found among the total 105 strains. The rate of diversity of the patterns by RFLP analysis with IS6110 for the M. tuberculosis strains in this study was $77.1 \%$. The minimum estimate for the proportion of TB that was due to transmission in East Azerbaijan Province is $23 \%$ [(35-11)/105]. If low-copy number strains would
A

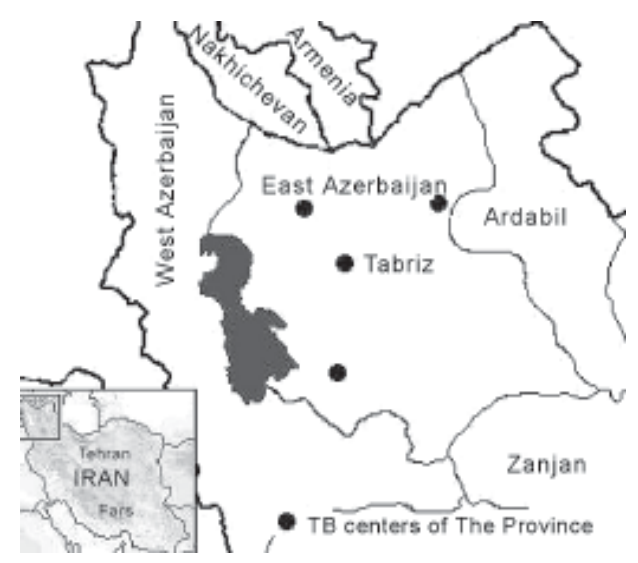

B

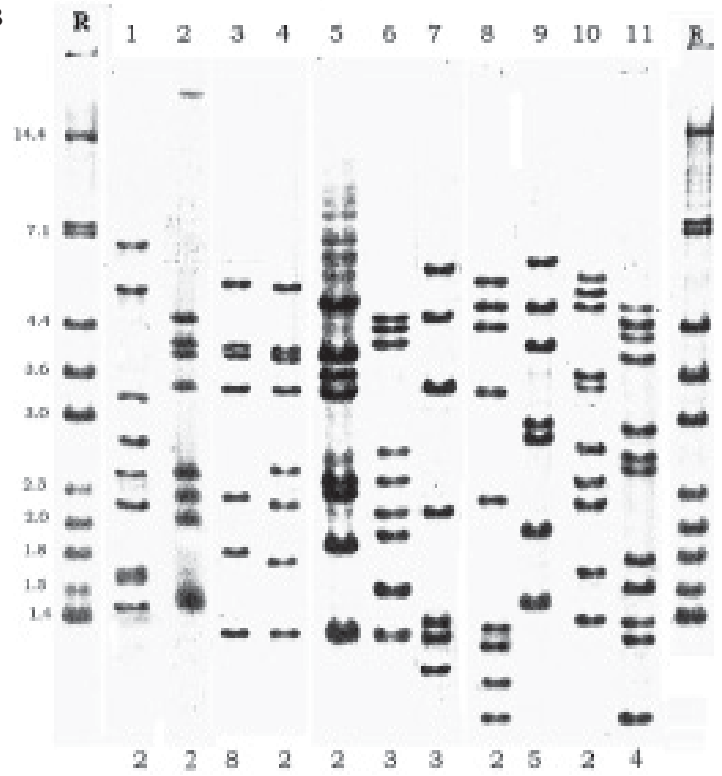

Fig. 1-A: map of the Northwest region of Iran; B: lanes - 1-11: restriction fragment length polymorphism (RFLP) patterns that was shared by at least two patients, the number at the bottom of figure shows number of patients with the same pattern; R: RFLP pattern of Mycobacterium tuberculosis reference strain Mt14323

have been included, clustering would even be less.

Characteristics of the clusters - The largest cluster comprised eight patients, who were all residents of Tabriz. Five of these patients were female and three of them knew each other; although our epidemiologic data do not allow to confirm this, transmission by contact or by frequenting the same place. The rest were residents from different parts of the city and no epidemiological linking was detected; however, all were suffering from poor living conditions. The second cluster was made up of five patients: three were from Tabriz and the others were from Maraghe, about $200 \mathrm{~km}$ away from Tabriz; no connection between the patients was detected. Another cluster was composed of four patients from different cities around Tabriz; two of them would commute to Tabiz. Two other clusters harbored three patients and the remaining six clusters comprised two patients, who were all from Tabriz. One of the 
smallest clusters containing two Iranian patients shared RFLP pattern with one strain of Nakhichevaneese patient that shows the transmission of infection probably from that region.

Comparison of IS6110 RFLP patterns with other Iranian strains - The clustered and non-clustered patterns were compared to those of other 192 patterns that were previously obtained from various parts of the country (of these 192 patterns, 54 were previously obtained from North-West of Iran). Out of 11 clusters of our study only one ( $2.8 \%$ of isolates) was found to have the same pattern as an isolate that was previously observed in Northwest of Iran. Non-clustered isolates shared 21 RFLP fingerprints ( $20 \%$ of isolates) with other Iranian strains, however, by removing previous patterns of the region from the comparison the percentage of identical patterns reduced to $6.6 \%$.

Risk factors associated with clustering - To identify risk factors associated with recent transmission, 35 clustered patients were compared with 70 non-clustered patients (Table). We did not observe any statistically significant differences in the rate of clustering for age, sex and site of TB ( $p>0.05)$. Among isolates, $40.7 \%$ of drugsensitive strains compared with $8.3 \%$ of drug-resistant strains, were clustered. The resistant strains were harbored in two smallest clusters, one strain was SM and INH resistant and the other was INH resistant. Statistical analysis showed significant differences between clustered and non-clustered patients for resistant to any drug ( $\mathrm{p}<$ $0.05)$.

\section{DISCUSSION}

IS6110-based DNA fingerprinting of M. tuberculosis has proven to be highly effective in detecting the sources of infection and in providing data for improving the control programs of tuberculosis. In this study, we used IS6110-RFLP typing to investigate active tuberculosis transmission in East Azerbaijan Province of Iran.

Of the 105 isolates in this study, nine strains $(8.6 \%)$ showed fewer than six copies of IS6110. Other studies showed similar data: $5.4 \%$ of strains from Tehran (Farnia et al. 2004) and $3.2 \%$ of strains from Fars Province had low copies of IS6110 (Doroudchi et al. 2000). Interest- ingly, very different data were obtained from Khorasan Province, where $38 \%$ of the isolates showed low or no copies of IS6110 (Farnia et al. 2001). The percentage of isolates containing low copy number of IS6110 in East Azerbaijan is lower than that observed in regions such as Malaysia (Dale et al. 1999), India (Narayanan et al. 2002), and Turkey (Durmaz et al. 2003). These finding indicate that IS6110-RFLP typing can be used without additional typing markers for this area. Also, our study detected 11 clusters, of which the majority was comprised of two or three patients; such data suggest that tuberculosis in this region of Iran is likely due to micro-epidemics.

By comparing our patterns with those obtained in previous studies, only seven isolates had RFLP patterns identical to patterns observed previously in other parts of the country. This low rate of similarity was also reported by Farnia et al. (2001) and is probably due to the distance between the studied areas and the lack of immigration between the areas. However, since RFLP analysis was not performed in all regions of the country, including in neighboring provinces, the true extent of clustering among patients of this region with patients elsewhere in Iran is probably underestimated.

We found $33.3 \%$ clustering among M. tuberculosis strains, suggesting that the majority of the tuberculosis cases in East Azerbaijan are due to reactivation. It is known that in mixed populations the degree of DNA polymorphism is greater (Van Embden et al. 1993). Although immigration from other parts of the country is almost inexistent in Tabriz, there is considerable number of patients from Nakhichevan (during our study, $11.8 \%$ of the initial strains were isolated from Nakhichevaneese patients); these could import new strains and lead to the high genetic diversity of M. tuberculosis genotypes. Furthermore, it should be noticed that the study was performed during a period of six months only, and because of the characteristics of disease transmission and development, a study using a larger time frame should be performed to evaluate the real clustering rate.

In a study on TB transmission in Paris, male sex is a risk factor for TB-clustering (Gutirrez et al. 1998). In the present study however, clustering, although not significant, was higher for female than for male TB patients. This might be due to discrimination of the female popula-

TABLE

Risk factors for clustering of tuberculosis in the East Azerbaijan

\begin{tabular}{|c|c|c|c|c|}
\hline$\underline{\text { Risk factor }}$ & $\begin{array}{c}\text { No. of patients } \\
(\%)\end{array}$ & $\begin{array}{l}\text { No. of clustered } \\
\text { patients }(\%)\end{array}$ & $\begin{array}{c}\text { No. of non-clustered } \\
\text { patients }(\%)\end{array}$ & $\mathrm{P}$ value \\
\hline \multicolumn{5}{|l|}{ Age (years) } \\
\hline$\leq 45$ & $45(42.9)$ & $15(42.9)$ & $30(42.9)$ & 1.00 \\
\hline$>45$ & $60(57.1)$ & $20(57.1)$ & $40(57.1)$ & \\
\hline \multicolumn{5}{|l|}{ Sex } \\
\hline Male & $60(57.1)$ & $19(54.3)$ & $41(58.6)$ & 0.676 \\
\hline Female & $45(42.9)$ & $16(45.7)$ & $29(41.4)$ & \\
\hline \multicolumn{5}{|l|}{ Site of TB } \\
\hline Pulmonary & $96(91.4)$ & $30(85.7)$ & $66(94.3)$ & 0.156 \\
\hline Extra pulmonary & $9(8.6)$ & $5(14.3)$ & $4(5.7)$ & \\
\hline Resistance to any drug & $24(22.9)$ & $2(5.7)$ & $22(31.4)$ & 0.0001 \\
\hline
\end{tabular}


tion, as reflected by lower education, more poverty, and malnutrition. Generally, young age is a risk factor for recent transmission (Alland et al. 1994, Small et al. 1994, Maguire et al. 2002) but in our study, no difference was observed between the younger or older age categories; unemployment and generalized poor living condition could be the reason for this. Another contrast to other studies (Shafer et al. 1995, Kruuner et al. 2001, Vukovic et al. 2003) was our findings that drug-resistant strains are less likely to be in a cluster than drug-sensitive strains ( $\mathrm{P}$ $=0.0001)$. It has been suggested that drug sensitive strains are more transmissible and the absence of drug resistant strains in the largest clusters supports this suggestion.

We can conclude that IS6110 DNA fingerprinting helped us to find epidemiological links between some TB cases and that this technique estimate better the magnitude of recent transmission of the disease in the Province. However, a longer period of study should be performed to confirm some of the risk factors that are different from many forementioned studies.

\section{ACKNOWLEDGMENTS}

To Davood Habibzadeh from Research Center for tuberculosis of Tabriz for assistance in obtaining patient information and Mehrnoosh Doroudchi from Immunology Department of Shiraz University of Medical Sciences for providing M. tuberculosis 14323.

\section{REFERENCES}

Alland D, Kalkut GE, Moss AR, McAdam RA, Hahn JA, Bosworth W, Drucker E, Bloom BR 1994. Transmission of tuberculosis in New York city: an analysis by DNA fingerprinting and conventional epidemiologic methods. $N$ Engl J Med 330: 1710-1716.

Bauer J, Yang Z, Poulsen S, Andersen AB 1998. Results from 5 years of nationwide DNA fingerprinting of Mycobacterium tuberculosis complex isolates in a country with a low incidence of M. tuberculosis infection. J Clin Microbiol 36: 305-308.

Bhanu N V, van Soolingen D, van Embden JDA, Dar L, Pandey RM, Seth P 2002. Predominance of a novel Mycobacterium tuberculosis genotype in the Delhi region of India. Tuberculosis 82: 105-112.

Dahle UR, Sandven P, Heldal E, Caugant DA 2001. Molecular epidemiology of Mycobacterium tuberculosis in Norway. J Clin Microbiol 39: 1802-1807.

Dale JW, Nor RM, Ramayah S, Tang TH, Zainuddin ZF 1999. Molecular epidemiology of tuberculosis in Malaysia. J Clin Microbiol 37: 1265-1268.

Diaz R, Gomez RI, Rstrepo R, Rumbaut R, Sevy-court J, Valdivia JA, Van Soolingen D 2001. Transmission of tuberculosis in Havana, Cuba: a molecular epidemiological study by IS6110 restriction fragment length polymorphism typing. Mem Inst Oswaldo Cruz 96: 437-443

Doroudchi M, Kremer K, Basiri E A, Kadivar MR, van Soolingen D, Ghaderi AA 2000. IS6110-RFLP and spoligotyping of Mycobacterium tuberculosis isolates in Iran. Scans J Infect Dis 32: 663-668.

Durmaz R, Gunal S, Yang Z, Ozerol IH, Cave MD 2003. Molecular epidemiology of tuberculosis in Turkey. Clin
Microbiol Infect 9: 873-877.

Farnia P, Mohammadi F, Fadda G, Sanguinetti M, Ghazisaeed K, Tabatabaei SJ, Posteraro B, Mansoori D, Bahadori M, Masjedi MR, Velayati AA 2001. Transmission pattern of tuberculosis using RFLP-based IS6110. Arch Irn Med 4: 177-182.

Farnia P, Mohammadi F, Masjedi MR, Varnerot A, Zarifi AZ, Tabatabee J, Douraghei M, Ghazisaeedi K, Mansorri D, Bahadori M, Vincent V, Gutierrez C, Velayati AA 2004. Evaluation of tuberculosis transmission in Tehran: using RFLP and spoligotyping methods. J Infect 49: 94-101.

Gutierrez MC, Vincent V, Aubert D, Bizet J, Gaillot O, Lebrun L, Le Pendeven C, Le Pennec MP, Mathieu D, Offredo C, Pangon B, Pierre-Audigier C 1998. Molecular fingerprinting of Mycobacterium tuberculosis and risk factor for tuberculosis transmission in Paris, France, and Surrounding Area. J Clin Microbiol 36: 486-492.

Hermans PWM, van Soolingen D, Dale JW, Schuitema AR, McAdam RA, Catty D, Van Embden JDA 1990. Insertion element IS986 from Mycobacterium tuberculosis: a useful tool for diagnosis and epidemiology of tuberculosis. J Clin Microbiol 28: 2051-2058

Kiers A, Drost AP, van Soolingen D, Veen J 1997. Use of DNA fingerprinting in international source case finding during a large outbreak of tuberculosis in the Netherlands. Int J Tuberc Lung Dis 1: 239-245.

Kremer K, van Soolingen D, Frothingham R, Haas WH, Hermmans PWM, Martin C, Palittapongarnpim P, Plikaytis BB, Riley LW, Yakrus MA, Musser JM, Van Embden JDA 1999. Comparison of methods based on different molecular epidemiological markers for typing of Mycobacterium tuberculosis complex strains: interlaboratory study of discriminatory power and reproducibility. J Clin Microbiol 37: 2607-2618.

Kruuner A, Hoffner SE, Sillastu H, Danilovits M, Levina K, Svenson SB, Ghebremichael S, Koivula T, Kallenius G 2001. Spread of drug-resistant pulmonary tuberculosis in Estonia. J Clin Microbiol 39: 3339-3345.

Maguire H, Dale JW, McHugh TD, Butcher PD, Gillespie SH, Costetsos A, Al-Ghusein H, Holland R, Dickens A, Marston L, Wilson P, Pitman R, strachan D, Drobniewski FA, Banerjee DK 2002. Molecular epidemiology of tuberculosis in London 1995-7 showing low rate of active transmission. Thorax 57: 617-622.

Narayanan S, Das S, Garg R, Hari L, Bhaskara Rao V, Frieden TR, Narayanan PR 2002. Molecular epidemiology of tuberculosis in a rural area of high prevalence in South India: implications for disease control and prevention. J Clin Microbiol 40: 4785-4788.

Niemann S, Rusch-Gerdes S, Richter E, Thielen H, HeykesUden H, Diel R 2000. Stability of IS6110 restriction fragment length polymorphism patterns of Mycobacterium tuberculosis strains in actual chains of transmission. J Clin Microbiol 38: 2563-2567.

Pineda-Garcia L, Ferrera A, Hoffner SE 1997. DNA fingerprinting of Mycobacterium tuberculosis strains from patients with pulmonary tuberculosis in Honduras. J Clin Microbiol 35: 2393-2397.

Small PM, Hopewell PC, Singh SP, Paz A, Parsonnet J, Ruston DC, Schecter GF, Daley CL, Schoolnik GK 1994. The epi- 
demiology of tuberculosis in San Francisco: a populationbased study using conventional and molecular methods. N Engl J Med 330: 1703-1709.

Shafer RW, Small PM, Larkin C, Singh SP, Kelly P, Sierra MF, Schoolnik G, Chirgwin KD 1995. Temporal trends and transmission patterns during the emergence of multidrug-resistant tuberculosis in New York City: a molecular epidemiologic assessment. J Infect Dis 171: 170-176.

Van Embden JDA, Cave MD, Crawford JT, Dale JW, Eisenach KD, Gicquel B, Hermans P, Martin C, McAdam R, Shinnick TM 1993. Strain identification of Mycobacterium tuberculosis by DNA fingerprinting: recommendations for a standardized methodology. J Clin Microbiol 31: 406-409.
Van Soolingen D, de Haas PEW, Hermans PWM, van Embden JDA 1994. DNA fingerprinting of Mycobacterium tuberculosis . Methods Enzymol 235: 196-205.

Vukovic D, Rusch-Gerdes S, Savic B, Niemann S 2003. Molecular epidemiology of pulmonary tuberculosis in Belgrade, Central Serbia. J Clin Microbiol 41: 4372-4377.

Warren RM, Van der Spuy GD, Richardson M, Beyers N, Borgdorff MW, Behr MA, Van Helden PD 2002. Calculation of the stability of the IS6110 banding pattern in patients with persistent Mycobacterium tuberculosis disease. J Clin Microbiol 40: 1705-1708.

WHO 2004. Global tuberculosis control. WHO report. WHO/ HTM/TB/2004.331, Geneva. 
